\section{AB1017 VERTEBRAL FRACTURES ARE LIKELY TO OCCUR IN LUMBAR VERTEBRA IN PATIENTS WITH OSTEOPOROSIS AND EVEN IN OSTEOPENIA}

Y. Jiang, D. Lin, X. Guo, M. Zhao, L. Fang, Z. Chen, X. Li, X. Zheng, Z. Liao, J. Gu Rheumatology, THE THIRD AFFILIATED HOSPITAL OF SUN YAT-SEN UNIVERSITY, Guangzhou, China

Background: Osteoporosis is a common disease, which can lead to fracture New diagnosis includes fracture of the vertebral bodies and hips, T-scores of bone mineral density (BMD) less than 2.5 or osteopenia together with humeral, forearm or the pelvis facture. Vertebral assessment should be considered in some conditions. ${ }^{1}$

Objectives: Our study was to investigate the condition of osteoporosis in patients who underwent bone mineral density in our hospital and fracture status according to lateral X-ray of cervical, thoracic and lumbar vertebra.

Methods: Patients were enrolled from September to December in 2017 in the Third Affiliated Hospital of Sun Yat-sen University. Demographic information, past medical history, and clinical information were collected by two rheumatologists. Bone mineral density measured by Dual Energy X-ray Absorptiometry was performed based on clinical needs. Patients with osteoporosis or osteopenia were asked to have X-ray scan of cervical, thoracic and lumbar vertebra. The Statistical Package for Social Sciences (SPSS) software version 21 was used for all data management and analysis.

Results: Of all the 210 patients, $60(28.6 \%)$ were male patients. $59.5 \%$ of female patients were in post-menopause stage. Mean age was $57.60 \pm 13.17$ years.124 patients were asked to perform BMD by the rheumatologists. 20 patients did the test after they saw an endocrinologist. 40 patients did the test after they saw an orthopedist. 102 patients had T-scores less than 2.5. 61 patients had osteopenia according to BMD. 22 patients had fracture according to past history or X-ray scans' findings. 10 patients had multiple fractures. The most frequent fractures were located in L1 (nine patients) and L2 (four patients). The other parts included L3, L5, C7, T12, T6, T8, and T9. Two patients had ankle or humeral fractures before because of injury. Vertebral fractures were founded in $5(8.2 \%)$ of the patients with T-scores of -2.5 to -1 during this study.

Conclusions: Lateral X-ray scans of the vertebra can detect vertebral fractures in patients with osteopenia according to BMD scores, even in patients less than 50 -year-old. Osteoporosis could be underestimated without measurement of the vertebra. The most frequent vertebra fracture happens in L1 .

\section{REFERENCE:}

[1] Gallacher SJ, Gallagher AP, McQuillian C, Mitchell PJ, Dixon T (2007) The prevalence of vertebral fracture amongst patients presenting with non-vertebral fractures. Osteoporos Int 18, 185-192.

Disclosure of Interest: Y. Jiang: None declared, D. Lin: None declared, X. Guo: None declared, M. Zhao: None declared, L. Fang: None declared, Z. Chen: None declared, X. Li: None declared, X. Zheng: None declared, Z. Liao Grant/research support from: National Natural Sciences Foundation of China [grant number 81201372], J. Gu Grant/research support from: the 5010 Subject of Sun Yat-sen University (2007023)

DOI: 10.1136/annrheumdis-2018-eular.5051

crystal diseases, metabolic bone diseases and bone diseases other than osteoporosis

\section{$\mathrm{AB} 1018$ \\ INTRAVENOUS NERIDRONATE IN THE TREATMENT OF BONE MARROW OEDEMA SYNDROME: EFFICACY AND SAFETY OF TWO DIFFERENT TREATMENT SCHEDULES}

A. Lurati ${ }^{1}$, A. Laria ${ }^{1}$, P. Faggioli ${ }^{2}$, M. Marrazza ${ }^{1}$, D. Mazzocchi ${ }^{1}$, A. Gilardi ${ }^{2}$, A. Tamburello ${ }^{2}$, L. Castelnovo ${ }^{2}$, K.A. Re ${ }^{1}$, A. Mazzone ${ }^{2} .{ }^{1}$ Rheumatology Unit, FORNAROLI HOSPITAL; ${ }^{2}$ MEDICINA INTERNA, ASST OVEST MILANESE OSPEDALE CIVILE DI LEGNANO E CUGGIONO, LEGNANO, Milan, Italy

Background: Bone Marrow Oedema Syndrome (BMES) is a severely disabling pain syndrome without a definite treatment well established.

Objectives: The aim of this monocentric prospective trial was to test the efficacy and the safety of the amino-bisphosphonate neridronate in patients with BMES administered in two different schedules.

Methods: one hundred seventy-three patients with BMES at various joints were consecutively assigned to I.V. infusion of $100 \mathrm{mg}$ neridronate given four times over 10 days (Group A) or alternatively to I.V. infusion of $100 \mathrm{mg}$ every 21 days over 63 days (Group B). At baseline (T0) and after 90 days from the first infusion we performed a MRI (T2). We assessed a 0-100 mm pain VAS in each patient at $\mathrm{TO}$, at the day of the last infusion (T1: day 10 for group A and day 63 for group B) and at T2. Primary outcome was to evaluate the MRI changes, secondary endpoint was the VAS change.

Results: we observed a significant improvement in MRI with the resolution of bone marrow oedema present at T0 $(\mathrm{p}<0.01)$, without a significant difference between Group A and Group B. Visual analogue scale (VAS) score decreased significantly during the study in both groups $(p<0.05)$ without a significant difference between the two treatment groups $(p>0.1)$.

Conclusions: In patients with BMES, the infusions of neridronate $100 \mathrm{mg}$ every 21 days over 3 months or alternately every 3 days over 10 days are associated with clinically relevant and persistent benefits without significant differences between the two treatment-schedules. These results provide conclusive evidence that the use of bisphosphonates, at appropriate doses, is the treatment of choice BMES

Disclosure of Interest: None declared

DOI: 10.1136/annrheumdis-2018-eular.4007

\section{AB1019 PATIENTS COMPLIANCE TO CHRONIC GOUT THERAPY WHEN ADMINISTERED BY DIFFERENT MEDICAL PROFESSIONALS}

A. Sarapulova ${ }^{1}$, O. Teplyakova ${ }^{1}$, A. Popov ${ }^{1}$, T. Popova ${ }^{2}$, P. Palabugina ${ }^{1} .{ }^{1}$ URALS STATE MEDICAL UNIVERSITY; ${ }^{2}$ City Clinical Hospital 40, Ekaterinburg, Russian Federation

Background: in everyday practice chronic gout patients are frequently consulted by general practitioners, surgeons, cardiologists and other specialists. In general, chronic gout patients have been reported to be quite incompliant, but it remains unclear whether low compliance depends on the specialty of the prescribing physician. $^{1}$

Objectives: to compare the clinical course of gout in patients consulted by different specialists and to identify factors of low patients' compliance in Russia.

Methods: cross-sectional study included 56 chronic gout patients aged 31 to 82 (median 54 years). Average gout symptoms duration was 6.8 years, average attacks frequency was 6.4 per year. Tofi were present in $21.4 \%$ of patients. All subjects were divided into three groups: Group 1 consisted of treatment naive patients at primary rheumatologist visit, Group 2 and Group 3 included patients who had previously been treated. Group 2 subjects were visiting both non-rheu matologists and rheumatologists. Group 3 were managed by rheumatologists strictly according to the EULAR evidence-based recommendations. ${ }^{2}$

Results: Group 1 primary consulted rheumatologists at the age of $47.3 \pm 14.5$, Group 2 patients were assessed at the age of 58.4 \pm 15.2 , and Group 3 were aged 51.2 \pm 13.5 . Disease symptoms duration was maximal in Group 2 (10.6 \pm 10.6 years) while 5 years in Groups 1 and Group 3. Flares frequency was the lowest in Group 3 (2.2 \pm 1.8 per year), while in Group 2 it was extremely high - $(10,58 \pm 10,56$ per year). The incidence of tofi and urolithiasis was lowest in the Group 3 whereas every third treatment naive patient had tophi or/and urolythiasis. To relieve gouty arthritis vast majority of patients used NSAIDs, though at $50 \%$ strength of the recommended dose. Only $9 \%-14 \%$ of flares were controlled by colchicine in Groups 2 and 3. Colchicine prevention of flares was prescribed only in $45 \%$ of cases by rheumatologists. The most frequent urate-lowering therapy (ULT) was allopurinol, it was taken only by $63 \%$ of patients of the third group and $35.7 \%$ in the second group. While patients in the third group took the drug daily, the other patients did not follow the administration scheme. Serum creatinine level was the lowest (87.5 $\pm 16.8 \mu \mathrm{mol} / \mathrm{L}$ ) in Group 3, being the highest in treatment of naïve patients (102.7 $\pm 30.0 \mu \mathrm{mol} / \mathrm{L}$ ). Serum uric acid target level was achieved only in the compliant Group 3 patients $(343 \mu \mathrm{mol} / \mathrm{L})$, while Group 2 levels varied between 462-546 $\mu \mathrm{mol} / \mathrm{L}$, being the highest $(625 \mu \mathrm{mol} / \mathrm{L})$ in treatment naïve Group 1.

Low compliance risk factors were: age under 45 , absence of comorbidity and long term multiple drugs consumption.

Conclusions: chronic gout patients' compliance and quality of patient manage ment can be assessed as alarmingly low. Rheumatologists adhering to EULAR evidence-based approach to gout management can actually achieve recommended treatment targets. Both general practitioners and other specialists are in need of consistent educational program on gout management. Younger and comorbidity-free gout patients should be encouraged to follow attending physician's recommendations.

\section{REFERENCE:}

[1] Burrell A, Wong P, Ollendorf D, et al. Defining compliance/adherence and persistence: ISPOR Special Interest Working Group. Value Health 2005; 8: A194-5.

Disclosure of Interest: None declared DOI: 10.1136/annrheumdis-2018-eular.6976 